\title{
Two Years vs. One: The Relationship Between Dosage of Programming and Kindergarten Readiness
}

\author{
Charles J. Infurna*,a, Guillermo Montes ${ }^{b}$
}

\author{
Received \\ Revised \\ Accepted \\ 12 August 2020 \\ 16 October 2020 \\ 24 December 2020 \\ $\mathrm{DOI}$ \\ 10.26822 /iejee.2021.188 \\ "Correspondance Details: Charles J. Infurna. \\ Children's Institute, Department of Clinical and \\ Social Sciences in Psychology, \\ University of Rochester, USA \\ E-mail: cinfurna@childrensinstitute.net \\ ORCID: http://orcid.org/0000-0001-9960-440X \\ ${ }^{b}$ Guillermo Montes. St. John Fisher College, Ralph \\ C. Wilson, Jr. School of Education, Rochester, USA \\ E-mail: gmontes@childrensinstitute.ne† \\ ORCID: http://orcid.org/0000-0002-7980-6044
}

\begin{abstract}
This research study investigated the effects of preschool dosage on kindergarten readiness in an urban school district $(n=1,464)$. This study was guided by one research question: do children who attend two years of structured early childhood education programming (3-year- old and 4-year-old pre-k) demonstrate stronger academic skills than their peers who only attend one year of pre-k programming (4-year-old pre-k only)? Implementing univariate and multivariate logistic regression models, we found that children who attend two years of programming were $34 \%$ more likely to make a successful transition to kindergarten compared to their peers who only attended pre-k as 4-yearolds. Black students who attended two years experienced a greater benefit, with a 53\% increased likelihood of being kindergarten-ready.
\end{abstract}

\section{Keywords:}

Dosage of Programming, Early Childhood Education,

Preschool, Student Outcomes

\section{Introduction}

Public funding for early childhood education (ECE) for 3and 4-year-old children in the United States has seen an increased amount of spending and resources provided for the enhancement of programming over the past decade (Friedman-Krauss et al., 2018). Previous research has shown that children attending high-quality early learning programs can improve school readiness in transitioning to kindergarten (Duncan \& Magnuson, 2013; Yoshikawa et al., 2013). Recent proposals from the state level have initiated efforts to expand ECE to allow more children to enroll in full-day programming before transitioning to kindergarten (New York State Education Department [NYSED], 2020). These initiatives aim to serve not just more children but also younger children, addressing a need to provide quality ECE programming to children at-risk and those living in poverty (Jenkins et al., 2016). This expansion includes individual state increases in programming for 3-and 4-year-olds provided at the district level. The primary goal of these public preschool expansions is to ensure that more children living in poverty have access to high-quality ECE programming (Bassok et al., 2016). 
Many states, such as New York, provide some school districts grant funding above $\$ 1$ million to support fullday ECE programming for 3- and 4-year-old children (NYSED, 2020). The expansion of programming has provided more school districts in New York State the opportunity to expose young children to earlier forms of structured programming before the start of the kindergarten year (NYSED, 2020). Recently increased state funding has thus resulted in a greater number of children enrolled in ECE programming at an earlier age than in previous years (Ansari et al., 2019). Nationally, fewer than $20 \%$ of children under the age of 2 are enrolled in some type of ECE programming (National Survey of Early Care and Education Project Team, 2015). However, as children age, so does the percentage of enrollment. For example, approximately $35 \%$ of threeyear-old children and $60 \%$ of 4 -year-olds are enrolled in some type of early childhood programming across the country (Ansari et al., 2019). With state increases in funding, there is a growing need to further understand the effect that early educational programming exposure has on children before transitioning to kindergarten (Ansari et al., 2019), and whether any benefits persist and can be detected over time.

The objective of this study is to answer one key question: Are children who attend two years of programming better prepared to make a successful transition to kindergarten compared to their peers who only attend one year of pre-k programming? We use data collected from an ongoing longitudinal study serving an urban school district located in New York State (Infurna, Riter, \& Schultz, 2018) to compare student academic and developmental outcomes before they transition to school-aged kindergarten programming within the same school district. Three- and 4-yearold students who are enrolled in programming are served both by the school district and Community Based Organizations (CBO), such as Head Start and the School districts that offer full-day programming for both 3- and 4-year-old children are required to house at least $10 \%$ of children enrolled in programming in CBO's that will funnel children to the school district when entering kindergarten (NYSED, 2020).

This study extends prior findings from previous dosage studies in several ways. First, it compares the academic outcomes of three groups of children. One group of children did not have contact with early pre-kindergarten (EPK) programming. A second group of children were enrolled in EPK but had chronic attendance issues (NYSED, 2020). The third group of children had regular EPK attendance and also had matching fall/spring assessment outcomes.

The current study is similar to that conducted by Jenkins et al. (2016) in which Head Start students in the state of Oklahoma were compared based on whether children attended one or two years of programming at the Head Start and school-based level. This study also extends the recent work conducted by Ansari et al. (2019) in which they investigated the academic, social-emotional, and executive functioning of children. In their study, Ansari et al. (2019) hypothesized that children who attended a 3-year-old programming would have stronger academic skills at the 4-year-old entry compared to their peers who did not attend a 3 -year-old programming. Ansari et al. (2019) reported that students who attended 3-year-old programming outperformed their peers at school entry the following year in math, language, and literacy achievement. Unlike Jenkins et al. (2016) and Ansari et al. (2019), participants of this study were drawn from an urban school district located in New York State (Infurna et al., 2018). As such, this study is designed to make a rigorous statistical comparison between three groups of children in a sample consisting of children who had no contact with EPK, those with some contact with EPK, and students who attended a full year of EPK before transitioning to kindergarten in an urban school district in New York State.

\section{Background}

\section{ECE Programming in New York State}

New York State has seen a gradual rise of full-day 4-year-old ECE programming over the past decade (NYSED, 2020). School districts across New York can apply for grant funding that, in turn, would create more 4-year-old programming opportunities for children who otherwise would not be able to afford to attend full-day programming before the kindergarten year. As recent as the 2015-2016 academic year, New York State began offering school districts the opportunity to apply for grants that would create fullday programming for 3-year-old children (early prekindergarten; EPK). This development provided school districts with even greater opportunities to enroll more children in full-day pre-kindergarten programming who otherwise would not have been able to attend or enroll.

Head Start programs across New York State have offered full-day and half-day programming options for children for decades. However, not all children have access to programming due to a limited number of enrollment slots and locations. The opportunity for school districts to apply for ear-marked grant funding has allowed a greater proportion of children living in poverty to have access to full-day high-quality programming beginning at age 3. Since the inception of full-day 3-year-old funding, only approximately 70 of the over 600 school districts in New York State have been awarded funding (NYSED, 2020). 


\section{ECE Program Quality in New York State}

It is unclear how to gauge the success of 3- and 4-yearold programming with regard to successful readiness to transition to kindergarten in New York State. School districts that receive EPK and/or universal prekindergarten (UPK) full-day funding are offered a wide variety of curricula and classroom assessment tools for implementation (NYSED, 2020). As of completion of this study, New York State had not released EPK or UPK student outcome data, either at the school district level or as a state in the aggregate.

As part of the New York State EPK and UPK grant mandates, school districts are required to select a cognitive, social-emotional, and classroom qualityassessment tool. A majority of 3- and 4-year-old programs across the nation implement the Child Observation Record-Advantage (COR-Advantage) tool developed by HighScope (2014). The school district in which data were utilized for this study has implemented a version of the COR for over two decades (Infurna et al., 2018). Another popular student assessment tool that is offered to school districts in New York State includes the Woodcock-Johnson III (Woodcock et al., 2001). Two additional commonlyused classroom instruments that are offered to school districts, again that are mandated as part of receiving full-day EPK and UPK funding, are the Classroom Assessment Scoring System (CLASS) (Pianta et al., 2008) and the Early Childhood Environment Rating Scale3rd Edition (ECERS-3) (Harms et al., 2015). The CLASS observation tool measures the quality of interactions observed between the classroom teacher and students (Pianta et al., 2008; Infurna et al., 2018). The ECERS-3 observation tool also measures the quality of interactions between students and teachers, but includes items focused on measuring the quality of the physical environment in which the children are enrolled (Harms et al., 2015; Infurna et al., 2018). Similar to student cognitive outcome data, classroom quality outcomes are not reported by most of the participating EPK and UPK programs. One such school district annually produces a report that documents student outcomes and classroom quality observed in EPK and UPK programming (Infurna et al., 2018). Otherwise, the degree of the quality of preschool programming in New York State, either in the aggregate level or by school district, is unknown to the research team.

\section{Comparing Student Achievement by Dosage Effect}

The influence of program duration on student academic and social-emotional outcomes is essential to understand whether two years of programming is more beneficial than one year of programming to students before transitioning to kindergarten (Jenkins et al., 2016). Approximately $50 \%$ of Head Start children who enroll in a 3-year-old programming will also be enrolled as 4-year-olds for an additional year of programming before transitioning to kindergarten (Tarullo et al., 2010). The empirical evidence suggests that the more time spent in ECE programming before transitioning to kindergarten, the stronger the cognitive outcomes in children, compared to their peers with less time spent in center-based ECE programming (Dearing et al., 2009).

The evidence also suggests, however, that the impact of attending the first year of programming is generally greater in magnitude than that of the second year of attendance (Tarullo et al., 2013). Similarly, another intensive early-learning programming, such as the Perry Preschool Project, produced significant positive effects (Schweinhart, 2005) and other preschool programs produced substantial positive effects with only one year of program attendance (Gormley et al., 2005). Most recently, Jenkins et al. (2016) reported that no statistically significant differences could be detected between children who attended two years of Head Start programming and their peers who only attended Head Start programming as 4-year-olds. The purpose of this research study was to determine if attending two years of preschool programming was more beneficial than one year for children living in an urban school district in Western New York State.

\section{Method}

\section{Research Design and Analysis}

We posed the following research question: Do children who attend two years of structured ECE programming (3-year-old and 4-year-old pre-k) demonstrate stronger academic skills than their peers who only attend one year of pre-k programming (4-year-old pre-k only)?

We hypothesize that children who attend two years of programming will demonstrate stronger academic gains at the end of the pre-k year and be more ready to successfully transition to kindergarten than their peers who only attend one year of programming.

\section{Data}

\section{Participants}

Secondary data analysis was conducted focused on 3- and 4-year-old children enrolled in full-day programming through an urban school district in New York State. Upon receiving approval from the Western Internal Review Board (WIRB), data were used from the 2018-19 academic school year. The data collected from this ongoing longitudinal study come from multiple sources: direct cognitive assessments of 
children at the beginning (fall) and end of the school year (spring) conducted by the classroom teacher and administrative data collected by the school district and surrounding CBOs. Our research question focused primarily on children who had participated in a 3-year-old programming for the duration of the 2017-2018 academic year and who were also enrolled in a 4-year-old programming during the 2018-2019 school year, and on 4-year-old children who were enrolled in programming during the 2018-2019 school year. One group of children did not have contact with early pre-kindergarten (EPK) programming. A second group of children was enrolled in EPK but had chronic attendance issues (NYSED, 2020). The third group of children had regular EPK attendance and also had matching fall/spring assessment outcomes.

\section{Table 1}

Number and Age of Students by Group

\begin{tabular}{lccc}
\hline Age & $N$ & $M^{*}$ & SD \\
\hline No EPK & 888 & 53.49 & 3.54 \\
\hline Partial EPK & 335 & 54.03 & 3.38 \\
\hline Full EPK & 241 & 53.89 & 3.17 \\
\hline
\end{tabular}

Note: *Age in months.

Table 1 shows the number and average ages of participants in each of the three groups. As can be seen, the students were of similar ages. Out of the sample of 1,464 students, $61 \%$ had no contact with EPK. $39 \%$ of the sample of students had some contact with EPK. Of those, 58\% attended partially and 42\% completed the EPK program. Group one children had no EPK contact. Group two children had partial EPK contact (chronically absent; NYSED, 2020). The third group of children had matching fall/spring CORAdvantage data and were considered high-attenders (NYSED, 2020).

\section{Measures}

Child academic data were collected at three points in time during the academic year (November, March, June), which included all eight categories of the COR-Advantage (Highscope, 2014). Classroom teachers observed children throughout the day, wrote anecdotes of their observations, and provided a child developmentally-appropriate score of 1-7 on 35 different items that make up eight categories (Approaches to Learning, Social-Emotional Development, Physical Development \& Health, Language, Literacy, \& Communication, Math, Creative Arts, Science and Technology, and Social Studies) (HighScope, 2014). The authors of the COR-Advantage established a kindergarten-readiness criterion in their latest development instrument (HighScope, 2014). A child is considered kindergarten ready if they score
>= 3.75 on each category and have an overall CORAdvantage score $>=4.0$ (Highscope, 2014). The overall COR-Advantage score is derived from adding the scores of the eight categories and then dividing by eight.

\section{Analysis}

The sample was inspected using frequencies and cross-tabulations. Univariate logistic regression models were estimated to determine the likelihood of kindergarten readiness by group. Multivariate logistic models were estimated to control for student age, gender, and race/ethnicity. Finally, these multivariate logistic models were re-estimated for separate ethnic/ racial groups. The statistical significance was set at $p<$ .05 .

\section{Results}

Table 2 displays the demographics of the sample, showing a similar distribution by gender across the three groups. Regarding race and ethnicity, 7\% of White students in UPK had completed EPK, compared to $15 \%$ of Hispanic students and $19 \%$ of Black students. Partial attendance had a similar demographic pattern, with $14 \%$ of White students, $22 \%$ Hispanic students, and $25 \%$ of Black students. Students who were identified as other race/ethnicity mirrored the pattern of Black students in this sample.

\section{Table 2}

Demographics of the Sample

\begin{tabular}{lrrrrrr}
\hline & \multicolumn{2}{c}{ No EPK } & \multicolumn{2}{c}{ Partial EPK } & \multicolumn{2}{c}{ Full EPK } \\
\hline & $N$ & $\%$ & $N$ & $\%$ & $N$ & $\%$ \\
\hline Male* $^{2}$ & 437 & 49.21 & 182 & 54.33 & 117 & 48.55 \\
\hline White non-Hispanic & 118 & 79.73 & 20 & 13.51 & 10 & 6.76 \\
\hline Hispanic & 271 & 63.17 & 93 & 21.68 & 65 & 15.15 \\
\hline Black non-Hispanic & 448 & 56.07 & 200 & 25.03 & 151 & 18.90 \\
\hline Other race/ethnicity & 51 & 57.95 & 22 & 25.00 & 15 & 17.05 \\
\hline
\end{tabular}

Note: * remaining students are female

Table 3 shows the univariate and multivariate logistic regression models. In all cases, kindergarten readiness was the dependent variable. Univariate results showed that students who had attended EPK were 34\% more likely to be kindergarten ready by the end of UPK than students who had not attended EPK (OR 1.34, $p<.05)$. Although the odds ratio for the comparison between students who had partially attended EPK versus those who had not attended at all was smaller by $6 \%$, it was no longer statistically significant (OR 1.28, p> .05).

In the largest multivariate logistic analysis, we controlled for the student's age, gender, and race/ ethnicity. This multivariate analysis confirmed the 
univariate results for the comparison of full EPK versus no EPK, estimating a $37 \%$ increased likelihood of kindergarten readiness. Once controls are added to the model, the $6 \%$ differential between partial and full EPK remains, but is now statistically significant (OR 1.31, $p<.05)$.

\section{Table 3}

Logistic Models on Kindergarten Readiness at the end of UPK

\begin{tabular}{lcccc}
\hline & \multicolumn{2}{c}{$\begin{array}{c}\text { Partial EPK vs. } \\
\text { No EPK }\end{array}$} & \multicolumn{2}{c}{$\begin{array}{c}\text { Full EPK vs. } \\
\text { No EPK }\end{array}$} \\
\hline & OR & $95 \% \mathrm{Cl}$ & OR & $95 \% \mathrm{Cl}$ \\
\hline Univariate model & 1.28 & $(0.99-1.65)$ & $1.34^{*}$ & $(1.01-1.79)$ \\
\hline Multivariate model & $1.31^{*}$ & $(1.01-1.69)$ & $1.37^{*}$ & $(1.02-1.84)$ \\
\hline Restricted to White students & 0.47 & $(0.18-1.26)$ & 1.11 & $(0.27-4.61)$ \\
\hline Restricted to Hispanic students & 1.04 & $(0.64-1.68)$ & 1.27 & $(0.73-2.20)$ \\
\hline Restricted to Black students & $1.70^{*}$ & $(1.20-2.39)$ & $1.53^{*}$ & $(1.05-2.24)$ \\
\hline
\end{tabular}

In addition, we estimated multivariate logistic regression models for racial/ethnic subgroups of students. These results show that the effect size was higher for Black students with a $53 \%$ increased likelihood to be kindergarten ready by the end of the UPK year, and a 70\% chance for those who attended EPK partially.

Because the majority of the students in the study sample were Black, the analyses restricted to White and Hispanic students are probably underpowered. However, small sample sizes do not influence the effect size, which is quite different from the univariate overall results. Hispanic students who attended full EPK had an effect size of 1.27, while White students had a smaller effect size of 1.11 . The results for partial EPK attendees were weaker with only a $4 \%$ increased likelihood for Hispanic students and a negative effect size for White students. Again, these differences were non-significant, which is likely the result of the small sample size.

\section{Discussion}

\section{Conclusions}

The purpose of this research study was to determine if two years of preschool programming better prepared children than one year of preschool to make a successful transition to kindergarten. Our sample consisted of three groups of children; a) no contact with EPK programming, b) partial EPK contact, and c) full year EPK contact who were enrolled in both school-based and community-based programming within the umbrella of an urban school district. The current study adds to the existing body of empirical literature on the dosage effects of early preschool entry for children and the effect of early entry on cognitive development before making the transition to kindergarten, as defined by school readiness (HighScope, 2014).

This study provides evidence that in an urban school setting, EPK attendance may boost kindergarten readiness at the end of the UPK year. The effect is moderate, with our best estimate being a $37 \%$ increased likelihood of kindergarten readiness. As expected, partial EPK attendance had a weaker effect by about $6 \%$. We also provide weaker evidence that these results may differ for various ethnic or racial groups. These results mirror those presented by Karoly et al. (2015), which reported that more time spent in structured ECE programming resulted in stronger developmental gains. Our results also support those reported by Loeb et al. (2004), which suggest that earlier entry and prolonged duration of programming yielded greater cognitive gains for children entering programming at 2.5 years of age while remaining enrolled through age 4. This was in comparison to peers who either did not attend programming at all (similar to a group of children in this study) or who entered at a later age. Our findings also support those reported by Puma et al. (2012) that students enrolled in Head Start programming at age 3 made greater language gains than their peers who enrolled as 4-year-olds.

Zaslow et al. (2010) reported that stronger developmental outcomes were associated with more hours of ECE attendance. However, our study did not focus on time as defined by hours of attendance, but rather how many days a child attended (NYSED, 2020) and whether attendance resulted in matching fall/ spring cognitive-developmental outcome data.

In 2007, Loeb et al. found that Black preschool students benefitted more from full-day programming than did their peers. Our outcomes for Black students support those reported by Loeb et al. (2007). In our case, we found stronger partial attendance effects for Black students, while there were non-significant effects for White and Hispanic students. Even if the results had been significant for these two subpopulations, the effects of EPK were estimated to be substantially weaker - $27 \%$ for Hispanic students and $11 \%$ for White students. Partial attendance effects were even weaker. Thus, EPK attendance had a powerful association with kindergarten readiness at the end of the UPK year in our sample, which may have been concentrated in a particular subgroup of students.

\section{Limitations of the Study}

None of the groups were randomized and, thus, the groups are nonequivalent in both measured 
and unmeasured characteristics. Attribution of the increased likelihood of the EPK attendance needs to be confirmed by future randomized studies. Our measure of kindergarten readiness relied exclusively on the form of assessment (teacher-completed CORAdvantage) and the results may be different using other measures of kindergarten readiness. Finally, the results of this study may not be generalizable outside of the particular urban school district studied, as other EPK programs may differ in substantial ways from the one that was studied here. The analysis for White and Hispanic students may have been underpowered, but as mentioned above, low statistical power should not influence effect size.

\section{Acknowledgments}

The authors would like to acknowledge the ESL Foundation for supporting this research project through Grant \# SG-1905-02793. We would also like to thank the many early childhood education teachers who provide high-quality programming to the youngest learners in our community.

\section{References}

Ansari, A., Pianta, R. C., Whittaker, J. V., Vitiello, V. E., \& Ruzek, E. A. (2019). Starting early: The benefits of attending early childhood education programs at age 3. American Educational Research Journal, 56(4), 1495-1523.

Bassok, D., Miller, L. C., \& Galdo, E. (2016). The effects of universal state pre-kindergarten on the child care sector: The case for Florida's voluntary prekindergarten program.

Dearing, E., McCartney, K., \& Taylor, B. A. (2009). Does higher quality early child care promote low-income children's math and reading achievement in middle childhood? Child Development, 80, 1329-1349.

Duncan, G. J., \& Magnuson, K. (2013). Investing in preschool programs. The Journal of Economic Perspectives, 27, 109-132.

Friedman-Krauss, A., Barnett, W. S., Weisenfeld, G. G., Kasmin, R., DiCrecchio, N., \& Horowitz, M. (2018). The state of preschool 2017. National Institute for Early Education Research.

Gormley, W. T., Gayer, T., Phillips, D., \& Dawson, B. (2005). The effects of universal pre-K on cognitive development. Developmental Psychology, 41, 872-884.
Harms, T., Clifford, R. M., \& Cryer, D. (2015). Early Childhood Environment Rating Scale-3rd Edition. Teachers College Press.

Highscope Educational Research Foundation. (2014). COR Advantage 1.5: Scoring guide. Highscope Press.

Jenkins, J. M., Farkas, G., Duncan, G. J., Burchinal, M., \& Vandell, D. L. (2016). Head Start at ages 3 and 4 versus Head Start followed by state pre-k: Which is more effective? Educational Evaluation and Policy Analysis, 38(1), 88-112.

Infurna, C. J., Riter, D., \& Schultz, S. (2018). Factors that Determine Preschool Teacher Self-Efficacy in an Urban School District. International Electronic Journal of Elementary Education, 11(1), 1-7.

Karoly, L., Kilburn, R., \& Cannon, J. (2005). Early childhood interventions: Proven results, future promise. Rand Corporation.

Loeb, S., Bridges, M., Bassok, D., Fuller, B., \& Rumberger, R. (2007). How much is too much? The influence of preschool centers on children's social cognitive development. Economics of Education Review, $26,52-66$.

Loeb, S., Fuller, B., Kagan, S., \& Carrol, B. (2004). Child care in poor communities: Early learning effects of type, quality, and stability. Child Development, $75,47-65$.

National Survey of Early Care and Education Project Team (2015). Tables on households' ECE usage and costs to parents. NORC at the University of Chicago.

New York State Education Department (2020). http:// www.p12.nysed.gov/funding/2018-19-epkexpansion-grant/awardee-list.html

Pianta, R. C., La Paro, K. M., \& Hamre, B. (2008). Classroom assessment scoring system (CLASS): Pre-K version. Paul H. Brookes.

Puma, M., Bell, S., Cook, R., Heid, C., Broene, P., Jenkins, F.,...Downer, J. (2012). Third grade follow-up to the head start impact study, final report. Office of Planning, Research and Evaluation, Department of Health and Human Services.

Schweinhart, L. J. (2005). Lifetime effects: The High/ Scope Perry Preschool Study Through Age 40 (Vol.14). High/Scope Educational Research Foundation. 
Tarullo, L. B., Aikens, N., Moiduddin, E., \& West, J. (2010). A second year of Head Start: Characteristics and outcomes of children who entered the program at age three. U.S. Department of Health and Human Services, Administration for Children and Families, Office of Planning, Research and Evaluation.

Tarullo, L. B., Xue, Y., \& Burchinal, M. R. (2013, April). Are two years better than one? Examining dosage of head start attendees using propensity score matching methodology. Paper presented at the Biennial Meeting of the Society for Research in Child Development, Seattle, WA.

Woodcock, R. W., McGrew, K. S., \& Mather, N. (2001). Woodcock-Johnson III NU Tests of Achievement. Riverside Publishing.

Yoshikawa, H., Weiland, C., Brooks-Gunn, J., Burchinal, M. R., Espinosa, L. M., Gormley, W.,...Zaslow, M. J. (2013). Investing in our future: The evidence base on preschool education. Foundation for Child Development, Society for Research in Child Development.

Zaslow, M., Anderson, R., Redd, Z., Wessel, J., Tarullo, L., \& Burchinal, M. (2010). Quality dosage, thresholds, and features of early childhood settings: A review of the literature. Office of Planning, Research, and Evaluation, U.S. Department of Health and Human Services. 